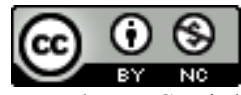

Jurnal Pendidikan Ilmu Pengetahuan Sosial Indoneia is licensed under A Creative Commons Attribution-Non Commercial 4.0 International License.

\title{
PENINGKATAN HASIL BELAJAR MATERI ANCAMAN TERHADAP INTEGRASI NASIONAL MELALUI IMPLEMENTASI MODEL PEMBELAJARAN DISCOVERY LEARNING DENGAN TEHNIK CONCEPT MAPPING BAGI SISWA KELAS X SMA NEGERI 1 WIROSARI
}

\author{
Mustikorini \\ SMAN 1 Wirosari \\ E-mail:mustikorini76@gmail.com
}

\begin{abstract}
Abstrak. Penelitian ini bertujuan peningkatan hasil belajar siswa terhadap materi Ancaman Terhadap Integrasi Nasional dan berapa besar peningkatan hasil belajar siswa pada aspek pengetahuan yang berbentuk tes tertulis dan aspek ketrampilan.Teknik pengumpulan data menggunakan lembar observasi, dan tes tertulis. Uji validitas data dilakukan oleh Expert Judgment dalam penelitian ini adalah teman sejawat yang lebih senior. Hasil penelitian menunjukkan bahwa (1) nilai rata-rata ulangan harian siswa yang tuntas pada prasiklus adalah 77,07(36\%), (2) nilai rata-rata pada siklus I adalah 77,23 (47\%), dan (3) nilai rata-rata pada siklus 2 adalah84,07 (78\%) pada siklus II. Dari hasilpenelitian tersebut dapat disimpulkan bahwa implementasi pembelajaran Discovery Learning dengan tehnik Concept Mapping dapat meningkatkan hasil belajar PPKn materi Ancaman Terhadap Integrasi Nasional di kelas X SMA Negeri 1 Wirosari Tahun Pelajaran 2018/2019 secara signifikan.
\end{abstract}

Keywords: Discovery Learning, Concept Mapping , Hasil Belajar, Ancaman Integrasi Nasional

\section{Pendahuluan}

Pembelajaran pada materi Ancaman Terhadap Integrasi telah berlangsung dengan metode diskusi kelompok, konvensional. Tugas diskusi kelompok diberikan kepada siswa, dengan harapan agar siswa dapat bekerja sama dengan siswa lain dalam memperdalam pemahaman materi pembelajaran. Tetapi dalam pelaksanaan, keaktifan siswa selama diskusi dan ketuntasan belajar belum maaksimal. Keaktifan siswa dalam diskusi kelompok peneliti ketahui dari siswa tertentu saja. Siswa tersebut bertindak sebagai ketua dan penyaji makalah dalam diskusi. Siswa yang tidak aktif dalam diskusi kelompok adalah siswa yang hanya berdiri di depan kelas bersama kelompoknya tetapi tidak memiliki aktivitas. Adapun siswa yang tidak maju presentasi biasanya hanya duduk, bermain hp, dan ngobrol dengan teman satu kelompok. Setelah semua kelompok melakukan presentasi, peneliti mengadakan penilaian secara individual dengan memberikan tes tertulis untuk mengukur aspek pengetahuan tidak menghasilkan nilai yang maksimal.Sehingga Model pembelajaran dengan tehnik tertentu diharapkan dapat meningkatkan hasil belajar siswa. Model pembelajaran Discovery Learning dengan tehnik concept mapping diharapkan dapat meningkatkan keaktifan dan hasil belajar siswa.

Menurut Bruner dalam Arends (2008), discovery learning merupakan sebuah metode pengajaran yang menekankan pentingnya membantu siswa untuk memahami struktur atau ide-ide kunci suatu disiplin ilmu, kebutuhan akan keterlibatan aktif siswa dalam proses belajar, dan keyakinan bahwa pembelajaran sejati terjadi melalui personal discovery (penemuan pribadi). Dalam metode discovery learning, siswa-siswa hendaknya belajar melalui berpartisipasi secara aktif dengan konsep-konsep dan prinsip-prinsip, agar mereka memperoleh pengalaman, dan melakukan eksperimen-eksperimen yang mengizinkan mereka untuk menemukan prinsip-prinsip itu sendiri.

Personal discovery (penemuan pribadi) oleh siswa dalam memahami konsep materi tertentu dapat dilakukan dengan mengaktifan siswa dalam proses pembelajaran. Diantaranya dengan menerapkan tehnik Concept Mapping. Novak dan Canas menyatakan Concept Mapping (Peta Konsep) adalah perangkat grafis yang dimaksudkan untuk mengorganisasikan atau menjelaskan pengetahuan. Esensi perangkat grafis ini adalah menggambarkan suatu konsep yang biasanya diwujudkan dalam bentuk lingkaran atau kotak, sedangkan hubungan antar konsep dinyatakan berupa 
garis hubung dua konsep. Arah pembacaan konsep dinyatakan dengan anak panah pada ujung garis hubung. Kata atau kata-kata atau frasa sebagai label ditempatkan pada garis hubung tersebut, dan menyatakan kekhasan hubungan antar kedua konsep.

Penerapan model pembelajaran Discovery Learning dengan tehnik Concept Mappingini, diawali dengan pembentukan kelompok. Di dalam kelompok tersebut mulamula setiap siswa diberi kesempatan untuk membuat peta konsep dari materi yang ingin dipahami oleh siswa. Selanjutnya siswa melakukan tinjauan (review) terhadap peta konsep yang dibuat secara mandiri dalam kelompoknya. Setelah melalui proses diskusi dalam kelompok, setiap kelompok untuk melakukan presentasi di depan kelas terkait dengan proposisi penting yang dicoba digambarkan dalam peta konsep. materi Ancaman terhadap Integrasi Nasional membutuhkan pemahaman konsep yang lebih, karena materi tersebut memiliki cakupan materi yang sangat luas dan banyak. Siswa akan kesulitan memahami dan menghafal materi tersebut. Hasil pembelajaran yang maksimal, siswa perlu menemukan sendiri cara untuk memahami dan menghafal materi tersebut. Dengan menggunakan model pembelajaran penemuan dengan membuat peta konsep, diharapkan dapat membantu siswa mempelajari materi Ancaman terhadap Integrasi Nasional, yang pada akhirnya dapat meningkatkan hasil belajar.

Berdasarkan latar belakang tersebut di atas, perlu dilakukaan penelitian mengenai peningkatan hasil belajar pada materi Ancaman terhadap Integrasi Nasional melalui penerapan model Discovery Learning dengan tehnik Concept Mappingsiswa kelas X SMA Negeri 1 Wirosari tahun pelajaran 2018/2019.

\section{Metode Penelitian}

Desain penelitian yang digunakan dalam penelitian ini adalah desain Penelitian Tindakan Kelas yang berbentuk siklus yang akan berlangsung lebih dari satu siklus bergantung pada tingkat keberhasilan dari target yang akan dicapai, dimana setiap siklus terdiri dari satu kali pertemuan. Pada setiap siklus terdiri atas: perencanaan (planning), tindakan (acting), pengamatan (observing), dan refleksi (reflecting).

Penelitian ini dilaksanakan di SMA Negeri 1 Wirosari pada kelas X tahun pelajaran 2018/2019. Veriabel yang digunakan terdiri dari variabel input yaitu siswa kelas $\mathrm{X}$ berjumlah 36 orang terdiri 15 putra dan 20 putri dengan usia rata-rata 15 tahun, sedangkan variabel proses berupa penggunaan model pembelajaran Discovery Learning dengan tehnik Concept Mapping. Variabel yang juga diamati yang berupa variabel output adalah proses belajar siswa berupa keaktifan siswa belajar dan interaksi dalam kerja kelompok.

Tehnik pengumpulan data menggunakan tehnik non tes yang berupa observasi dan dokumentasi, dan tehnik tes yang lakukan setiap akhir siklus.

Uji validitas dilakukan oleh Expert judgment, yang menjadi Expert Judgment dalam penelitian ini adalah teman sejawat yang lebih menguasai materi dan model pembelajaran.

Tehnik analisis data yang digunakan dalam penelitian ini adalah

- Lembar observasi, yang digunakan untu mengamati keaktifan siswa selama kegiatan belajar mengajar berlangsung, mulai dari pembuatan peta konsep sampai dengan presentasi hasil kerja kelompok. Analisis data keaktifan siswa yaitu dengan menghitung rata-rata keaktifan siswa dalam setiap pembelajaran, dengan rumus sebagai berikut (Depdiknas, 2003, p. 6).

\section{Rata-rata keaktifan $=\underline{\text { Jumlah siswa aktif }}$} Jumlah aspek

- Tes individu:

$$
\text { Nilai }=\frac{\text { Skoryangdiperole } h}{\text { SkorMaximum }} \times 100 \%
$$

- Rata - rata kelas

$$
\bar{x}=\frac{\sum x}{\sum N}
$$

Dengan keterangan sebagai berikut:

$\bar{x}=$ Nilai rata - rata

$$
\begin{aligned}
& \sum \mathrm{x}=\text { Jumlah semua nilai } \\
& \sum N=\text { Jumlah siswa }
\end{aligned}
$$

- Ketuntasan belajar

$$
\mathrm{P}=\frac{\text { Siswayangtuntasbelajar }}{\sum \text { siswa }} \times 100 \%
$$

Indikator beberhasilan penelitian dikatakan berhasil jika siswa dikatakan berhasil apabila keaktifan siswa dalam pembelajaran mencapai $80 \%$ dari keseluruhan siswa. Dan ketuntasan belajar secara individual telah mencapai nilai $\geq$ 70 dengan angka ketercapaian minimal $75 \%$ dari keseluruhan siswa

\section{HASIL PENELITIAN}

Deskripsi Kondisi Awal

Deskripsi awal penelitian ini, didasarkan pada partisipasi siswa dalam diskusi kelompok. Sebelum diberikan tehnik concept mapping , hanya beberapa siswa memiliki partisipasi dan kerjasama dalam diskusi kelompokdan saat presentasi.Adapun hasil pengamatan dapat dilihat pada tabel berikut :

Tabel 1. Hasil observasi keaktifan siswa kondisi awal

\begin{tabular}{|l|l|l|}
\hline Aspek yang diobservasi & $\begin{array}{c}\text { Aktif } \\
\text { (Jumlah siswa } \\
\text { dan \%) }\end{array}$ & $\begin{array}{c}\text { Tidak aktif } \\
\text { Jumlah siswa } \\
\text { dan \%) }\end{array}$ \\
\hline $\begin{array}{l}\text { 1. Proses mengumpul- kan } \\
\text { informasi } \\
\text { menganalisis }\end{array}$ & & \\
$\begin{array}{l}\text { a. Partisipasi } \\
\text { b. Kerjasama }\end{array}$ & $14(39 \%)$ & $22(61 \%)$ \\
2. Presentasi & $15(42 \%)$ & $21(58 \%)$ \\
a. Bertanya & $6(17 \%)$ & $30(83 \%)$ \\
b. Menyanggah & $15(42 \%)$ & $21(58 \%)$ \\
\hline
\end{tabular}




\begin{tabular}{|c|c|c|}
\hline $\begin{array}{ll}\text { c. } & \text { Berpendapat } \\
\text { d. } & \text { Menjawab } \\
& \text { pertanyaan }\end{array}$ & $16(44 \%)$ & $20(56 \%)$ \\
\hline Rata-rata & $(38 \%)$ & $(62 \%)$ \\
\hline
\end{tabular}

Setelah semua kelompok melakukan presentasi, peneliti mengadakan penilaian secara individual dengan untuk mengukur aspek pengetahuan (knowledge) dengan memberikan tes tertulis.siswa yang belum meraih nilai sesuai dengan kriteria ketuntasan minimal (kkm) atau kurang dari 70 (tujuh puluh ) sebanyak 23 (dua puluh tiga) dari jumlah 36 siswa peserta ulangan harian dengan rata-rata 55.63. Siswa yang sudah mencapai nilai 70 ke atas sebanyak 13 (tiga belas) siswa dengan nilai rata-rata 77,54. Adapun rekap hasil ulangan harian dapat dilihat pada tabel berikut :

Tabel .2 Rekap Hasil Ulangan HarianKondisi Awal

\begin{tabular}{|c|c|c|c|c|}
\hline \multirow{2}{*}{ No } & \multirow{2}{*}{$\begin{array}{c}\text { Aspek } \\
\text { Nilai }\end{array}$} & \multicolumn{3}{|c|}{ Pra siklus } \\
\cline { 3 - 5 } & & Jml siswa & Nilai Rata-rata & Prosentase \\
\hline 1 & $\begin{array}{c}\text { Tidak } \\
\text { Tuntas }\end{array}$ & 23 & 45,95 & $64 \%$ \\
\hline 2 & Tuntas & 13 & 77,07 & $36 \%$ \\
\hline
\end{tabular}

Hasil ulangan harian KD 3.1 pada kondisi awal dapat dilihat dari grafik berikut :

\section{UH Kondisi Awal}

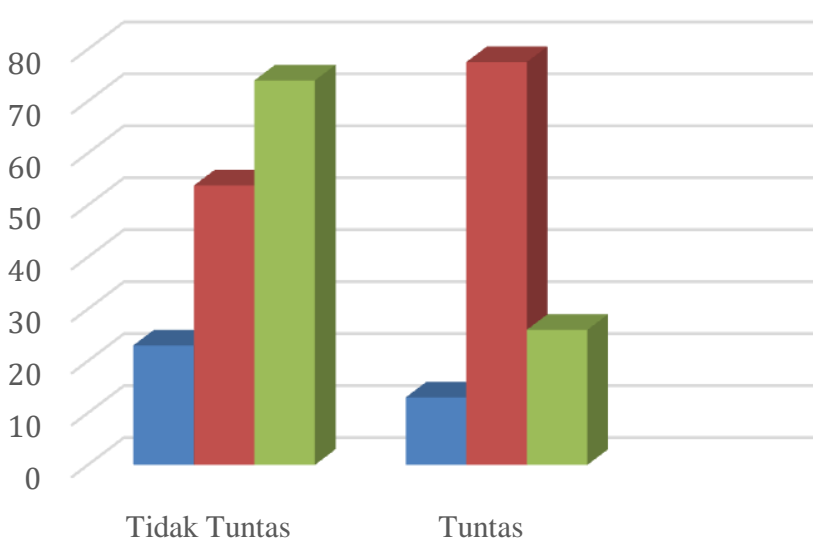

Jumlah siswa $\quad$ Rata-rata UH $\quad \mathrm{P}$

Dari hasil pengamatan selama proses pembelajaran dengan diskusi kelompok dan hasil ulangan harian tersebut penelitian menemukan hal-hal sebagai berikut :

a. Model diskusi yang digunakan dalam KBM dilaksanakan siswa, tetapi tidak semua siswa aktif dalam kelompok diskusinya. Siswa-siswa yang tidak aktif tersebut juga duduk bersama kelompoknya tetapi tidak memiliki aktivitas belajar yang tinggi.

b. Siswa yang aktif biasanya siswa tersebut bertindak sebagai ketua dan penyaji makalah dalam diskusi kelompok.

c. Hasil ulangan tulis menunjukkan siswa yang tidak aktif dalam diskusi mendapatkan nilai di bawah KKM.

Berdasarkan hasil deskripsi awal tersebut.,maka peneliti melakukan penelitian dengan membuat inovasi pembelajaran, berupa kolaborasi metode diskusi dengan tehnik peta konsep. Diharapkan inovasi ini bisa membantu siswa meningkatkan hasil belajar.

Siklus 1

Hasil obsevasi keaktifan siswa selama proses belajar mengajar dengan tehnik concept mapping dalam siklus 1 , siswa mulai memiliki partisipasi dan kerjasama dalam diskusi kelompok. Mulai terlihat beberapa siswa yang aktif pada saat presentasi. Hasil observasi aktifitas siswa dapat dilihat dari tabel berikut :

Tabel 3. Hasil observasi keaktifan siswa kondisi awal

\begin{tabular}{|l|c|c|}
\hline Aspek yang diobservasi & $\begin{array}{c}\text { Aktif } \\
\text { (Jumlah } \\
\text { siswa dan } \\
\%)\end{array}$ & $\begin{array}{c}\text { Tidak aktif } \\
\text { (Jumlah } \\
\text { siswa dan } \\
\%)\end{array}$ \\
\hline $1 . \quad$ Proses & & \\
mengumpulkan & & \\
informasi & $20(56 \%)$ & $16(44 \%)$ \\
menganalisis & $18(50 \%)$ & $18(50 \%)$ \\
a. Partisipasi & $15(42 \%)$ & $21(58 \%)$ \\
b. Kerjasama & $17(47 \%)$ & $19(53 \%)$ \\
$2 . \quad$ Presentasi & $18(50 \%)$ & $18(50 \%)$ \\
a. Bertanya & $19(53 \%)$ & $17(47 \%)$ \\
b. Menyanggah & & \\
c. Berpendapat & & $(50,46 \%)$ \\
d. Menjawab & $(49,54 \%)$ & \\
pertanyaan & & \\
\hline Rata-rata & & \\
\hline
\end{tabular}

Hasil ulangan tulis, Siswa yang belum meraih nilai sesuai dengan kriteria ketuntasan minimal (kkm) atau kurang dari 70 (tujuh puluh ) sebanyak 19 (sembilan belas) dari jumlah 36 siswa peserta ulangan harian dengan rata-rata 56.89. Siswa yang sudah mencapai nilai 70 ke atas sebanyak 17 (tujuh belas) siswa dengan nilai rata-rata 77,23.

Tabel .4 Rekap Hasil Ulangan Harian Siklus 1

\begin{tabular}{|c|c|c|c|}
\hline \multirow{2}{*}{ No } & Aspek Nilai & \multicolumn{2}{|c}{ Siklus 1 } \\
\cline { 3 - 4 } & & Jml siswa & Nilai Rata-ra \\
\hline 1 & $<$ KKM & 19 & 56,89 \\
\hline 2 & $>$ KKM & 17 & 77,23 \\
\hline
\end{tabular}

Dari hasil nilai ulangan harian siswa kelas yang dilakukan peneliti dapat dilihat pada grafik berikut : 


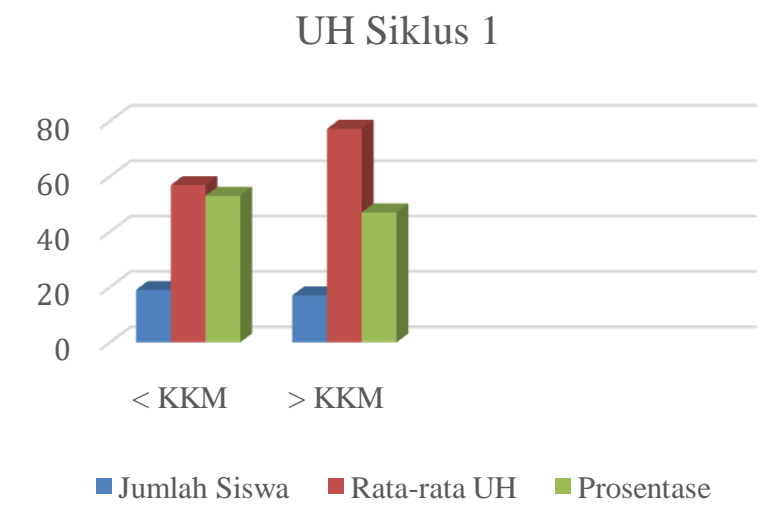

Grafik 2. UH Siklus 1

Dari hasil pengamatan peneliti menjumpai permasalahan sebagai berikut :

1) Model Discory Learning dengan tehnik concept mapping sudah digunakan dalam KBM, tetapi tidak semua siswa aktifberpartisipasi dan bekerjasama dalam kelompok diskusinya. Siswa-siswa yang tidak aktif tersebut juga duduk bersama kelompoknya tetapi tidak memiliki aktivitas belajar yang tinggi.

2) Pada saat presentasi untuk menyampaikan hasil kerja kelompok, siswa yang aktif biasanya siswa tersebut bertindak sebagai ketua, sekretaris, dan penyaji makalah dalam diskusi kelompok.

3) Hasil nilai post tes masih banyak siswa yang belum tuntas

Atas dasar beberapa kekurangan yang dihadapi guru dalam pelaksanaan pembelajaran maka peneliti memandang perlu untuk mengadakan perbaikan tindakan kepada siswa agar hasil belajar dapat maksimal.

Siklus 2

Hasil obsevasi keaktifan siswa selama proses belajar mengajar selama pelaksanaan siklus 2, siswa lebih aktif partisipasi dan kerjasama dalam diskusi kelompok. Dan pada saat presentasi hasil kerja kelompok terjadi peningkatan keaktifan siswa. Hasil observasi aktifitas siswa dapat dilihat dari tabel berikut :

Tabel 5. Hasil observasi keaktifan siswa kondisi awal

\begin{tabular}{|l|l|l|}
\hline Aspek yang diobservasi & $\begin{array}{c}\text { Aktif } \\
\text { (Jumlah siswa } \\
\text { dan \%) }\end{array}$ & $\begin{array}{c}\text { Tidak aktif } \\
\text { (Jumlah siswa } \\
\text { dan \%) }\end{array}$ \\
\hline $\begin{array}{l}\text { 1. Proses mengumpul- kan } \\
\text { informasi dan }\end{array}$ & & \\
menganalisis & $36(100 \%)$ & $0(0 \%)$ \\
a. Partisipasi & $36(100 \%)$ & $0(0 \%)$ \\
b. Kerjasama & & \\
2. Presentasi & $28(78 \%)$ & $8(22 \%)$ \\
a. Bertanya & $25(69 \%)$ & $11(31 \%)$ \\
b. Menyanggah & $27(75 \%)$ & $9(25 \%)$ \\
c. Berpendapat & $26(72 \%)$ & $10(28 \%)$ \\
d. Menjawab & & \\
\hline & pertanyaan &
\end{tabular}

\begin{tabular}{|l|l|l|}
\hline Rata-rata & $(82,41 \%)$ & $(17,59 \%)$ \\
\hline
\end{tabular}

Hasil ulangan tulis, Siswa yang belum meraih nilai sesuai dengan kriteria ketuntasan minimal $(\mathrm{kkm})$ atau kurang dari 70 (tujuh puluh ) sebanyak 8 (delapan) dari jumlah 36 siswa peserta ulangan harian dengan rata-rata 61,88 . Siswa yang sudah mencapai nilai $70 \mathrm{ke}$ atas sebanyak 28 (dua puluh delapan) siswa dengan nilai rata-rata 84,07.

\begin{tabular}{|c|c|c|c|c|}
\multicolumn{5}{|c|}{ Tabel .6. Rekap Hasil Ulangan Harian Siklus 2 } \\
\hline \multirow{2}{*}{ No } & $\begin{array}{c}\text { Aspek } \\
\text { Nilai }\end{array}$ & \multicolumn{3}{|c|}{ Siklus } \\
\cline { 3 - 5 } & & Jml siswa & $\begin{array}{c}\text { Nilai Rata- } \\
\text { rata }\end{array}$ & Prosentase \\
\hline 1 & $<$ KKM & 8 & 61,88 & $22 \%$ \\
\hline 2 & $>$ KKM & 28 & 84,07 & $78 \%$ \\
\hline
\end{tabular}

Dari hasil nilai ulangan harian siswa kelas yang dilakukan peneliti dapat dilihat pada grafik berikut :

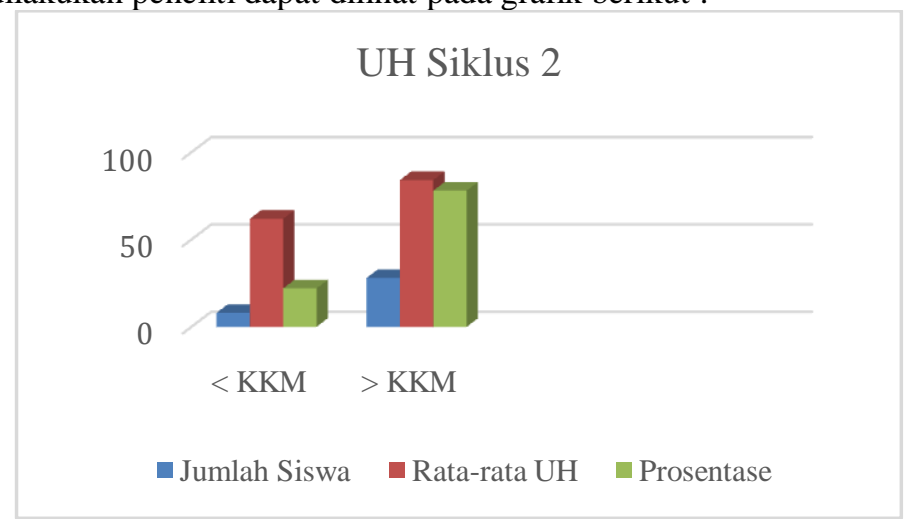

Grafik 3. UH Siklus 2

Dengan menerapkan kembali metode pembelajaran Discovery Learning dengan tehnik concept mapping, terjadi peningkatan hasil belajar peserta didik pada siklus II dibandingkan pada siklus I yaitu sebagai berikut :

1) Model Discory Learning dengan tehnik concept mapping sudah digunakan dalam KBM, semua siswa aktif berpartisipasi dan bekerjasama dalam kelompok diskusinya.

2) Pada saat presentasi untuk menyampaikan hasil kerja kelompok, semua siswa lebih aktif yang terlibat pada saat kelompok lain presentasi. Aktifitas bertanya, menyanggah, berpendapat, dan menjawab pertanyaan lebih meningkat.

3) Hasil nilai post tes mengalami peningkatan prsentase siswa yang mendapatkan nilai tuntas

Pembahasan antar Siklus

a. Perubahan kondisi awal ke siklus 1

Kondisi awal penelitian diperoleh data siswa yang belum meraih nilai sesuai dengan kriteria ketuntasan minimal $(\mathrm{kkm})$ atau kurang dari 70 (tujuh puluh ) sebanyak 23 (dua puluh tiga) dari jumlah 36 siswa peserta ulangan harian dengan rata-rata 45.95 . 
Siswa yang sudah mencapai nilai 70 ke atas sebanyak 13 (tiga belas) siswa dengan nilai rata-rata 77,07. Prosentase siswa yang nilai ulangan tulisnya kurang dari KKM sebanyak $64 \%$. Sedangkan nilai ulangan tulis siswa yang lebih dari KKM sebanyak $36 \%$.

Setelah diadakan penelitian siklus 1, diperoleh data siswa yang belum meraih nilai sesuai dengan kriteria ketuntasan minimal kurang dari 70 sebanyak 19 dari jumlah 36 siswa peserta ulangan harian dengan rata-rata 56,89. Siswa yang sudah mencapai nilai $70 \mathrm{ke}$ atas sebanyak 19 siswa dengan nilai rata-rata 77,23 . Prosentase siswa yang nilai ulangan tulisnya kurang dari KKM sebanyak $53 \%$. Sedangkan nilai ulangan tulis siswa yang lebih dari KKM sebanyak $47 \%$.

Tabel .7. Rekap Hasil Ulangan HarianKondisi Awal dan Siklus 1

\begin{tabular}{|c|c|c|c|c|c|c|c|c|c|c|c|c|}
\hline \multirow[b]{2}{*}{ No } & \multirow[b]{2}{*}{$\begin{array}{l}\text { Aspek } \\
\text { Nilai }\end{array}$} & \multicolumn{2}{|c|}{ Kondisi Awal } & \multicolumn{2}{|c|}{ Siklus 1} & \multirow[b]{2}{*}{$\begin{array}{c}\text { Peningkatan / } \\
\text { Penufunaz }\end{array}$} & \multirow{4}{*}{$\begin{array}{l}\text { Aspek } \\
\text { Nilai }\end{array}$} & \multicolumn{2}{|c|}{ Siklus 1} & \multicolumn{2}{|c|}{ Siklus 2} & \multirow{3}{*}{$\begin{array}{c}\text { Penin } \\
\text { gkatan } \\
/ \\
\text { Penur } \\
\text { unan }\end{array}$} \\
\hline & & $\begin{array}{l}\text { Jumlah } \\
\text { siswa }\end{array}$ & $\begin{array}{c}\text { Rata- } \\
\text { rata }\end{array}$ & $\begin{array}{l}\text { Jumlah } \\
\text { siswa }\end{array}$ & $\begin{array}{c}\text { Rata- } \\
\text { rata }\end{array}$ & & & \multirow{2}{*}{$\begin{array}{c}\text { Jumla } \\
\text { h } \\
\text { siswa }\end{array}$} & \multirow[t]{2}{*}{$\begin{array}{l}\text { Rata } \\
\text {-rata }\end{array}$} & \multirow{2}{*}{$\begin{array}{c}\text { Jumla } \\
\text { h } \\
\text { siswa }\end{array}$} & \multirow[t]{2}{*}{$\begin{array}{c}\text { Rata- } \\
\text { rata }\end{array}$} & \\
\hline 1 & $<\mathrm{KKM}$ & 23 & 45,95 & 19 & 56,89 & $10,94 \%$ & & & & & & \\
\hline 2 & $>\mathrm{KKM}$ & 13 & 77,07 & 17 & 77,23 & $0,16 \%$ & & & & & & unan \\
\hline \multirow{2}{*}{\multicolumn{6}{|c|}{$\begin{array}{c}\text { Tabel .8. Rekap Prosentase Ketuntasan Ulangan Hariandari } \\
\text { Kondisi Awal dengan Siklus } 1\end{array}$}} & \begin{tabular}{l|l|} 
& 1
\end{tabular} & KKM & 19 & $\begin{array}{c}56,8 \\
9\end{array}$ & 8 & 61,88 & $\begin{array}{c}4,99 \\
\%\end{array}$ \\
\hline & & & & & & 2 & $\begin{array}{c}>\mathrm{KK} \\
\mathrm{M}\end{array}$ & 17 & $\begin{array}{c}77,2 \\
3\end{array}$ & 28 & 84,07 & $\begin{array}{c}6,84 \\
\%\end{array}$ \\
\hline
\end{tabular}

\begin{tabular}{|c|c|c|c|c|c|}
\hline \multirow[b]{2}{*}{ No } & \multirow{2}{*}{$\begin{array}{l}\text { Aspek } \\
\text { Nilai }\end{array}$} & \multicolumn{2}{|c|}{ Kondisi Awal } & \multicolumn{2}{|c|}{ Siklus 1} \\
\hline & & $\begin{array}{c}\text { Jumlah } \\
\text { siswa }\end{array}$ & $\%$ & $\begin{array}{c}\text { Jumlah } \\
\text { siswa }\end{array}$ & $\%$ \\
\hline 1 & $<\mathrm{KKM}$ & 23 & 64 & 19 & 53 \\
\hline 2 & $>\mathrm{KKM}$ & 13 & 36 & 17 & 47 \\
\hline
\end{tabular}
dengan grafik sebagai berikut :

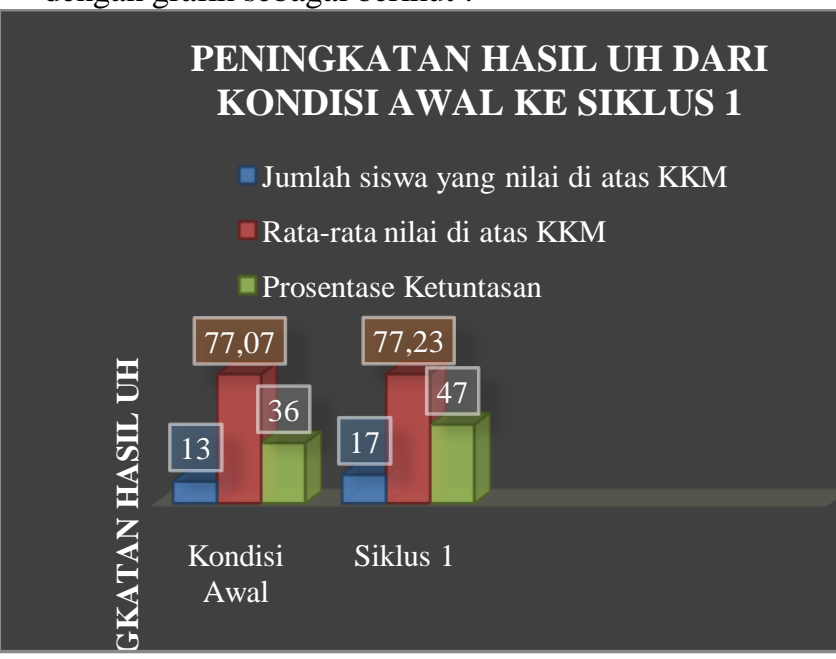

Grafik 4. Peningkatan UH Kondisi Awal ke

Siklus 1

b. Perubahan dari siklus 1 ke siklus 2
Penelitian siklus 1, diperoleh data siswa yang belum meraih nilai sesuai dengan kriteria ketuntasan minimal kurang dari 70 sebanyak 19 dari jumlah 36 siswa peserta ulangan harian dengan rata-rata 56,89 . Siswa yang sudah mencapai nilai 70 ke atas sebanyak 17 siswa dengan nilai rata-rata 77,23. Prosentase siswa yang nilai ulangan tulisnya kurang dari KKM sebanyak $53 \%$. Sedangkan nilai ulangan tulis siswa yang lebih dari KKM sebanyak $47 \%$.

Peningkatanhasilbelajar

darisikluspertamakesikluskedua, terlihat dari jumlah siswa yang memperoleh nilai di atas KKM dari 17 siswa menjadi 28 siswa. Rata-rata nilai ulangan harian siswa yang mencapai nilai diatas KKM dari 77,23 menjadi 84,07.Sedangkan Prosentase siswa yang tuntas dari $47 \%$ menjadi $78 \%$.

Tabel 9. Rekap Hasil Ulangan HarianSiklus 1 dan Siklus 2

Peningkatan /
Penurunan

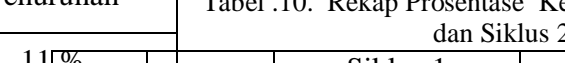

\begin{tabular}{|c|c|c|c|c|c|c|}
\hline$\%$ & & Siklı & & Sikl & & Peningk \\
\hline${ }^{\%} \mathrm{No}$ & $\begin{array}{l}\text { Aspek } \\
\text { Nilai }\end{array}$ & $\begin{array}{c}\text { Jumlah } \\
\text { siswa }\end{array}$ & $\%$ & $\begin{array}{c}\text { Jumlah } \\
\text { siswa }\end{array}$ & $\%$ & $\begin{array}{c}\text { atan / } \\
\text { Penurun } \\
\text { an }\end{array}$ \\
\hline 1 & $\begin{array}{c}< \\
\text { KKM }\end{array}$ & 19 & 53 & 8 & 22 & $31 \%$ \\
\hline 2 & $\begin{array}{c}>\mathrm{KK} \\
\mathrm{M}\end{array}$ & 17 & 47 & 28 & 78 & $31 \%$ \\
\hline
\end{tabular}

Peningkatan hasil ulangan harian dari siklus 1 sampai pelaksanaan siklus 2 dapat digambarkan dengan grafik sebagai berikut :

\section{Peningkatan Hasil UH dari Siklus 1 ke} Siklus 2

- Jumlah siswa yang mendapat nilai di atas KKM

$\square$ Nilai rata-rata UH di atas KKM

口 Prosentase ketuntasan

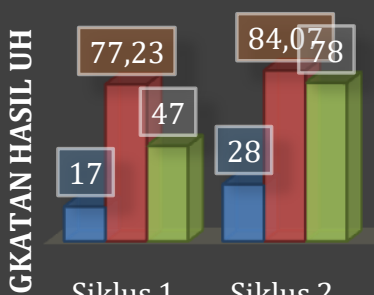

Siklus $1 \quad$ Siklus 2

Grafik 5. Peningkatan UH Siklus 1 ke Siklus 2 
c. Perubahan antara Kondisi Awal, Siklus1 dan Siklus 2

Inovasi mengajar yang dilakukan peneliti, dengan menggunakan model pembelajaran Discovery Learning dengan tehnik Concept Mapping diperoleh data peningkatan hasil ulangan harian dari kondisi awal ke siklus 1 dan ke siklus 2 dapat dilihat pada grafik berikut ;

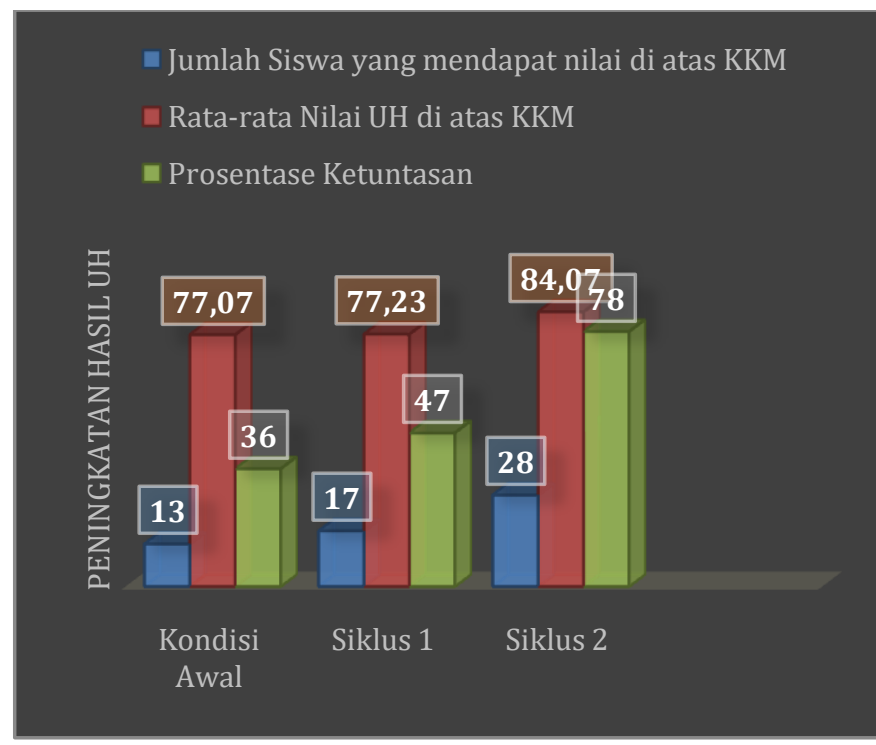

Grafik 6.Hasil Penelitian Antar Siklus

Berdasarkan grafik di atas terlihat bahwa ada peningkatan yang signifikan dari kondisi awal, siklus pertama dan siklus kedua. Indikator pencapaian dalam penelitian ini adalah prosentase siswa yang mencapai ketuntasan belajar dalam materi Ancaman Terhadap Integrasi Nasional mengalami peningkatan setelah mengimplementasikan pembelajaran Discovery Learning dengan tehnik concept mapping .

Dengan demikian dalam penelitian ini, dapat menjawab rumusan masalah yang dikemukakan oleh peneliti yaitu Implementasi metode pembelajaran Discovery Learning dengan tehnik Concept Mapping dapat meningkatkan hasil belajar pada materi Ancaman Terhadap Integrasi Nasional di kelas SMA Negeri 1 Wirosari Semester Genap Tahun Pelajaran 2018/2019.

\section{KESIMPULAN DAN SARAN}

Berdasarakan hasil perbaikan pembelajaran yang telah dilaksanakan dapat diperoleh kesimpulan sebagai berikut :

1. Melalui penerapan metode pembelajaran Discvery Learning dengan tehnik Concept Mapping di SMA Negeri 1 Wirosari, Kecamatan Wirosari, Kabupaten Grobogan pada Semester Genap Tahun Pelajaran 2018/2019 materi Ancaman Terhadap Integrasi Nasional terlihat pada:

a. Pada praSiklus dari 36 siswa, hanya $13(36 \%)$ siswa yang sudah mendapat nilai lebih dari Kriteria Ketuntasan Minimal (KKM) yang telah ditentukan yaitu sebesar 70, berarti masih ada 23 $(45,95 \%)$ siswayang tidak tuntas

b. Pada siklus Idilakukandengan menggunakan metode pembelajaran Discovery Learning dengan tehnik Concept Mapping dari 36 peserta didik, sudah $17(47 \%)$ peserta didik yang sudah mendapat nilai lebih dari Kriteria Ketuntasan Minimal (KKM) yang telah ditentukan yaitu sebesar 70, dan hanya ada 19 (53\%) peserta didik yang tidak tuntas.

c. Pada Siklus II dengan menerapkan kembali metode pembelajaran Discovery Learning dengan tehnik Concept Mapping dari 36 peserta didik, sebanyak $28(78 \%)$ peserta didik yang sudah mendapat nilai lebih dari Kriteria Ketuntasan Minimal (KKM) yang telah ditentukan yaitu sebesar 70, berarti hanya $8(22 \%)$ peserta didik yang masih tidak tuntas.

2. Ketuntasan hasil belajar siswa Kelas X MIPA 2 di SMA Negeri 1 Wirosari, Kecamatan Wirosari, Kabupaten Grobogan Semester Genap Tahun Pelajaran 2018/2019 pada mata pelajaran PPKn materi Ancaman Terhadap Integrasi Nasional, hal ini dibuktikan dari peningkatan jumlah siswa yang nilainya lebih dari KKM pada pra siklus sebanyak 13 siswa meningkat pada siklus I setelah menggunakan metode pembelajaran Discovery Learning dengan tehnik Concept Mapping menjadi 17 siswa, dan akhirnya bisa di tingkatkan lagi pada siklus II menjadi 28 siswa.

Dengan demikian dengan menggunakan metode pembelajaran Discovery Learning dengan tehnik Concept Mapping dalam proses pembelajaran dapat meningkatkan keaktifan siswa, sehingga hasil belajar siswa Kelas X MIPA 2 di SMA Negeri 1 Wirosari, Kecamatan Wirosari, Kabupaten Grobogan Semester Genap Tahun Pelajaran 2018/2019 pada mata pelajaran PPKn materi Ancaman Terhadap Integrasi Nasional dapat meningkat.

\section{DAFTAR PUSTAKA}

Aqib Zainal.2013. Model-Model, Media dan Strategi Pembelajaran Konstektual, Bandung : Yrama Widya

Suryobroto.2009, Proses Belajar Mengajar di Sekolah, Jakarta, Rineka Cipta.

Warsono dan Harianto.2012, Pembelajaran Aktif,Bandung, PT Remaja Rosdakarya Offset

Eka Ikhsanudin. 2014, Pembelajaran Model Discovery Learning, diakses

Tanggal 4 Desember $2014 \mathrm{di}$

https://www.ekaikhsanudin.net/2014/12/pembelajaran -model-discovery-learning.html

Herdian. 2010, Metode Pembelajaran Discovery (Penemuan), diakses tanggal 27 Mei $2010 \mathrm{di}$ https://herdy07.wordpress.com/2010/05/27/m etode-pembelajaran-discovery-penemuan/

Abdul Gofur. 2016, Sintak Model Discovery Learning, diakses tanggal 20 Februari 2016 di 
https://modelpembelajaran1.wordpress.com/2016/02/ 20/sintak-model-discovery-learning/

Nur Sumiyarsih. 2016, Sintak Model Pembelajaran Discovery, PBL, dan PBJL, diakses tanggal 2 Oktober 2016 di

https://nursbio.wordpress.com/2016/10/02/sintaksmodel-pembelajaran-discovery-pbl-dan-pjbl/

Muchlisin Riadi. 2017, Metode Pembelajaran Penemuan (Descovery Learning, diakses Tanggal 13 September 2017 di https://www.kajianpustaka.com/2017/09/metodepembelajaran-penemuan-discovery-learning.html Kementerian Pendidikan dan Kebudayaan. 2018, Pendidikan Pancasila dan Kewarganegaraan untuk SMA/MA/SMK/MAK Kelas X, Jakarta, Gramedia.

. 2014, Permendikbud Nomor 104 Tahun 2014 tentang Penilaian Hasil Belajar Oleh Pendidik pada Pendidikan Dasar dan Menengah, tersedia di https://akhmadsudrajat.files.wordpress.com/2014/11/ permendikbud-no-104-tahun-2014.pdf. 